\title{
Emotional experience in individual and cooperative traditional games. A gender perspective
}

\author{
Pere Lavega ${ }^{1 *}$, Unai Saez de Ocáriz ${ }^{2}$, Francisco Lagardera ${ }^{1}$, Jaume March, Nuria Puig ${ }^{2}$ \\ 1 National Institute of Physical Education of Catalonia (INEFC), University of Lleida (Spain). \\ 2 National Institute of Physical Education of Catalonia (INEFC), University of Barcelona (Spain). \\ 3 Methodology \& Statistics Unit, University of Lleida (Spain).
}

\begin{abstract}
Título: Experiencia emocional en juegos tradicionales individuales $\mathrm{y}$ cooperativos. Una perspectiva de género.

Resumen: Este estudio exploró el efecto del género (GE) y la composición del género del grupo (CGEC) en experiencias emocionales de hombres y mujeres cuando participaron en diferentes juegos. Para formular nuestra hipótesis se hizo uso del marco teórico elaborado a partir de las teorías de Lazarus y Bisquerra en relación al constructo de la competencia emocional y el bienestar y su relación con estereotipos de género, así como la teoría de acción motriz de Parlebas y resultados previos de la investigación empírica relativa a juegos, emociones y género. Los participantes (218 estudiantes universitarios, $\left.M_{\text {edad }}=20.3, D T=2.73\right)$ realizaron doce sesiones de Juegos individuales (IG) y de Juegos cooperativos (CG). Los resultados mostraron que GE y GGEC fueron predictores de la experiencia de emociones positivas y que los hombres expresaron más emociones negativas en ambos juegos. Los hallazgos muestran diferencias de género y podrían ayudar a los profesores de educación física a evitar actividades que promuevan jerarquías y desigualdades asociadas al género y a los estereotipos de sexo.

Palabras clave: Género; Educación Física; Estereotipos Emocionales; Composición del Género del Grupo; Juegos Tradicionales.
\end{abstract}

Abstract: This study explored the effect of gender (GE) and group gender composition (GGEC) on men's and women's experiences of emotions when taking part in different games. To formulate our hypotheses we used a theoretical framework formed by the theories of Lazarus and Bisquerra on the construct of emotional competence and well-being and their relationship with gender stereotypes, Parlebas's motor action theory and previous results of empirical research related to games, emotions and gender relations. The participants (218 university students, $M_{\text {age }}=20.3, S D=2.73$ ) completed twelve sessions of individual games (IG) and cooperative games (CG). The results showed that GE and GGEC were predictors of the experience of positive emotions and that males were more likely to experience negative emotions in both games. The findings highlight gender differences and could help physical education teachers to avoid activities that reinforce the hierarchies and inequalities associated with gender and sex role stereotypes.

Key words: Gender; Physical Education; Emotional Stereotypes; Group Gender Composition, Traditional Games.

\section{Introduction}

Sport as a social phenomenon brings a wide range of interpersonal experiences associated with different emotional experiences. These experiences may contribute towards participants' personality development, depending on whether the sports activities lead to positive, negative or ambiguous emotions (Bisquerra, Soldevila, Ribes, Filella, \& Agulló, 2005; Lavega, Filella, Lagardera, Mateu, \& Ochoa, 2013; Lazarus, 2000). It is therefore important to introduce emotional education into schools, since physical education (PE) classes are an excellent pedagogical framework within which to provide education in emotional competence.

The abilities related to perceiving, identifying and becoming aware of one's own emotions constitute the first stage of what is termed emotional competence, or intrapersonal intelligence (Denham, Bassett, \& Wyatt, 2007). Intrapersonal intelligence refers to knowledge about one's inner life: accessing one's emotions, evaluating the range of feelings that one feels, distinguishing between different emotions and giving them a name, and using emotions to interpret and guide one's behavior (Bisquerra et al., 2005). On the positive side, researchers have suggested that the ability to identify emotions is correlated with indices of well-being (Ciarrochi \& Scott, 2006). This is very important when it comes to educat-

* Correspondence address [Dirección para correspondencia]: Pere Lavega, National Institute of Physical Education of Catalonia (INEFC), University of Lleida, Complex Caparrella s/n, 25192 Lleida (Spain).E-mail: plavega@inefc.es ing students about emotional issues such as self-esteem and self-efficacy.

Moreover, emotions are culturally situated and young people are socialized to enact certain emotions, that is, to act with emotional intelligence in different socio-cultural contexts (Hochschild, 1983). This has led some authors to introduce the construct of emotional competence (Bisquerra et al., 2005; Ciarrochi \& Scott, 2006), a concept that involves three main processes: the understanding of emotion, the expression of emotion, and the regulation of emotion (Ciarrochi \& Scott 2006; Denham et al. 2007).

A conclusion to be drawn from research in this field is that university students, the teachers of tomorrow who intend to promote socio-emotional education programs, should be aware that emotions (emotional competence), insofar as they are social and cultural phenomena, can be taught. However, university students receive little training in emotional competences and interpersonal relationships (Schutz \& Pekrun, 2007). This is certainly the case of Spanish university courses on physical activity and sport (Lavega, Aráujo, \& Jaqueira, 2013).

This deficit is even greater when the problem is examined from the perspective of gender relations. Research on emotions and gender in Spain has produced some consistent findings in relation to emotional socialization and gender stereotypes.

Many PE teachers, for instance, reproduce the model of competitive sport in their classes, distributing boys and girls into unequal groups, without realizing that by doing so they may be promoting gender inequalities in favor of boys and implementing, albeit inadvertently, a hidden curriculum that 
transmits gender stereotypes (Castillo \& Montes, 2014; Lavega, Alonso, Etxebeste, Lagardera, \& March, 2014; Lavega, March, \& Filella, 2013; Vera, Moreno, \& Moreno-Murcia, 2009). It is therefore vital for PE teachers to understand the emotions generated by each of the activities they organize during their classes, depending on the group's gender composition. This will help them to improve students' emotional competence and create more equitable gender relations (Beltrán-Carrillo, Devís-Devís, Peiró-Vlert, \& Brown, 2012).

Using research conducted among university PE students in Spain, this paper aims to answer the following question: how do gender and group gender composition affect the intensity of the emotional experience of playing games?

This will help future PE teachers to ensure that the emotional component of PE classes is consistent with subjective well-being in a context of gender equity.

The theoretical framework for this research is based on:

(a) Parlebas's motor theory or motor praxeology.

(b) The theories of Lazarus and Bisquerra on the construct of emotional competence and well-being and their relationship with gender stereotypes.

(c) Previous results of empirical research related to games, emotions and gender relations (e.g., Lavega, Aráujo et al., 2013; Lavega, Filella, et al, 2014; Lavega, March et al., 2013; Lavega et al., 2014).

(d) Motor Action Domains and Emotions

Sporting games have enormous potential to stimulate emotions among those taking part. However, some games are more likely to stimulate certain emotions than others, and they may also do so to varying degrees of intensity. It is therefore necessary to have a classification that enables the relationships to be established between the different types of games and the emotional experiences they elicit. The theory of motor action, or motor praxeology (Parlebas, 2001) classifies games into four motor domains: (a) the psychomotor domain, in which there is no motor communication with other participants, examples being the long jump and ten-pin bowling; (b) the cooperative domain, in which participants must interact in an interdependent and mutually supportive way in order to achieve a shared goal, as occurs in team rhythmic gymnastics and singing games; (c) the purely opposition domain, in which participants compete against each other through actions that counter those of their rivals, sometimes involving physical contact, such as in judo, or perhaps simply escaping from one's pursuer in a game of tag; and (d) the cooperation-opposition domain, in which participants combine collaboration with teammates with opposition against their rivals, as occurs in soccer, dodgeball and red rover, all of which require motor communication that can be perceived by teammates but not by the rival team.

Each of these domains of motor action can be performed in competitive games (where there is a scoring system to determine the winner and loser) and non-competitive games (where there is no scoring system to compare participants' performances) (Etxebeste, 2012; Parlebas, 2001).
This method for classifying games has been used in previous studies to examine the emotional experiences of university students from different countries (Lavega, Aráujo et al., 2013; Lavega, March et al., 2013; Lavega et al., 2014), as well as those of primary school children (Sáez de Ocáriz, Lavega, \& March, 2013). The initial findings suggest that affective behaviors, especially the intensity of positive emotions, vary significantly, depending on which of the four motor action domains is used and whether the activity is competitive or non-competitive (Lavega et al., 2014).

\section{Emotions, Education and the Reproduction of Gen- der Relations}

In the context of education, a student's emotional experience will depend on his or her evaluation or appraisal of what goes on in different classes (Lazarus, 1991, 2000). All students, consciously or unconsciously, will evaluate the relevance of a pedagogical event (e.g., traditional games) with respect to a personal goal that is regarded as important. Emotions will be positive when the event implies progress towards a goal. Emotions will be negative when an obstacle is met, that is, when a goal cannot be reached, or in the face of threats or losses. However, there is also a third category which some authors refer to as "borderline or ambiguous emotions" (Lazarus 1991, 2000). These emotions may be either positive or negative or neither, depending on the circumstances. For example, surprise may be positive or negative, as it may be the result of a pleasant event (scoring a goal in an unexpected way) or an unpleasant one (conceding a goal in an unexpected way) (Bisquerra et al., 2005).

Kennedy Root and Denham (2010) note that gender is a critical moderator of what children learn about emotion and how they learn it, because culture determines the appropriateness of emotional displays for males and females. Specifically in Spain, women are stereotyped as being more emotional than men, and they are also said to be more emotionally expressive (e.g., Bolaños \& Jiménez, 2007; Del Castillo, Romero, González, \& Campos, 2012; Gartzia, Aritzeta, Balluerka, \& Barberá, 2012; Gutiérrez, Ruiz \& López, 2010). Greater female reporting of positive emotions emerges most clearly in situations involving cooperative interpersonal relationships, while individualism, independence and competing with others are consistent with the male roles (Lavega, 2006; Lavega, Aráujo et al., 2013; Lavega, March et al., 2013).

\section{Gender and Emotion in Traditional Games and in PE classes}

From a gender perspective, studies have suggested that boys and girls react differently when PE classes use competitive sport (Del Castillo et al., 2012; Vera et al., 2009).

In Spain, empirical research has shown that traditional games tend to assign males and females to stereotypical gender roles; although some traditional games may be played by either sex, others have generally been regarded as exclusive 
to males or females (e.g. Etxebeste, 2012; Lavega, 2006; Navarro \& Trigueros, 2009). Studies have also found that, whereas girls tend to play cooperative games, boys are much more likely to engage in the opposition domain or in various kinds of individual (psychomotor) games (Etxebeste, 2012; Lavega, Aráujo, et al., 2013; Lavega, Filella, et al., 2013; Sáez de Ocáriz et al., 2013). These stereotypes and gender roles associated with traditional games are internalized in early childhood (Navarro \& Trigueros, 2009; Lavega 2006).

Furthermore, empirical research has also found that group gender composition in PE classes influences students' emotions, with differences between boys' and girls' emotions (Lavega, Aráujo, et al., 2013; Lavega et al., 2014). For PE classes, reviews of the literature (e.g. Chalabaev, Sarrazin, Fontayne, Boiché, \& Clément-Guillotin, 2013; Keinman, 1999) suggest that both girls and boys prefer to have PE classes only with their same-sex peers. Boys say that girls put in less effort, whereas girls argue that mixed classes are less enjoyable because boys cooperate less and because unbalanced situations tend to arise. Both boys and girls report that in single-sex PE classes they perform better, receive more practice opportunities, compete harder, learn more, behave better, and are less fearful of injury (Williams, 2010).

\section{Hypotheses}

In light of the aforementioned theoretical framework, the hypotheses for the present study were as follows:

(1) Traditional games will lead to different experiences and intensities of positive, negative and ambiguous emotions. Previous studies have shown that the internal variables of traditional games (domain of motor action and competition) associated with other subject variables (gender, gender group composition) result in higher-intensity positive emotions, lower-intensity negative emotions, and intermediate-intensity ambiguous emotions (e.g. Lavega et al., 2014; Lavega, March et al., 2013). The same trend is expected in the present study.

(2) The main predictor variables for positive and ambiguous emotions will be subject variables (gender, gender group composition) and internal game variables (type of game in terms of interaction and competition).

The game is principally a source of pleasure (Parlebas, 2001), and subjective well-being can be generated both by participation in the game (Lavega, Aráujo et al, 2013) and by the gender of the participants (Bolaños \& Jiménez, 2007; Johnson, Prusak, Pennington, \& Wilkinson, 2011; Lavega, Aráujo et al., 2013).

(3) The variables associated with the gender perspective (gender, gender group) are predictors of negative emotions.

As researchers in Spain have shown, girls tend to play to cooperative games, whereas boys are much more likely to engage in individual games. When girls play characteristically male games, they may experience negative emotions (e.g., Sáez de Ocáriz et al., 2013). If boys and girls are grouped together, they may also experience negative emotions because traditional games tend to assign males and females to stereotypical gender roles (Hertenstein \& Keltner, 2011; Sáez de Ocáriz et al., 2013). Thus, one can assume that the gender perspective will be key to interpreting negative emotions.

\section{Method}

\section{Participants}

The sample comprised 218 undergraduates (59 females, $27.06 \%$; 159 males, $72.94 \%$; mean age $=20.3$ years, $S D=$ 2.73). This study formed part of the syllabus of the Motor Games Theory and Practice subject on a Physical Education and Sport Science degree at a Catalan university. Thus, all first-year undergraduates enrolled in this subject took part in the study. We divided the 218 participants into six groups (A-F), each with 33-37 students, with the same male-female ratio as for the other research students in the degree program: $27-33.7 \%$ male, $66.3-73 \%$ female. 177 participants $(81.2 \%)$ regularly took part in some kind of sport, whereas the remaining $41(18.8 \%)$ had no sporting background. All the students gave their consent to participate in the study, which was also approved by the research ethics committee of the University of Lleida (Spain).

\section{Instruments and Procedure}

\section{Educating Students' Emotions}

This study was also a pedagogical intervention (the Educating Emotions Program) that sought to raise awareness among future PE teachers of the importance of considering the researched variables so as to ensure that the emotional component of PE classes is consistent with subjective wellbeing in a context of gender equality. For this reason, participants first received three sessions (4.5 hours in total) of theoretical and practical training in emotions based on the model of Bisquerra (2003) and Lazarus (2000). In these sessions, students learned how to identify their own emotions through exercises involving game situations. They also learned how to use a Games and Emotion Scale (GES). After each game, they tried to identify their emotions, and any problems with recognizing their own emotions or with completing the GES were solved. After each session, there was a group discussion to help interpret the emotions experienced in each game. This ensured that data were collected under optimum conditions.

\section{Selection and use of traditional games}

Participants completed six sessions of 24 psychomotor (individual) games and six of 24 cooperative (team) games, each lasting 1.5 hours each. Each group took the sessions in a different order, to reduce the influence of any possible car- 
ry-over effects on the results. We selected the games based on the following criteria: (a) they were traditional games that were well-known in Spanish culture; (b) they were representative of psychomotor and cooperative games, such as those described in Table 1; (c) in both blocks (psychomotor and cooperative), two games were competitive and two were non-competitive; and (d) in each block, two sessions involved single-sex activities (i.e., an individual game played alongside participants of the same sex or a cooperative game played in a single-sex group), two sessions involved games played in unbalanced mixed-sex groups (with the usual malefemale ratio in each group), and the other two involved games played in balanced mixed-sex groups, with the same number of male and female participants. Because there were more males than females, some of the males in each group did two additional games in the single-sex group.

Table 1. Description of the Games used in the Educating Emotions Program.

\section{Type of game \\ PG with Competition \\ Example: Sack Race \\ PG without Competition \\ Example: Juggling}

Cooperative Games (CG)

CG with Competition

Example: Rope Jump

CG without Competition

Example: The Knot

\section{Description}

PG) There is no motor interaction between players.

Each player competes against another, either in parallel zones or by taking turns.

Each player stands inside a sack and must jump towards the finishing line, which is 15 meters away. The overall winner is the first person to win three races.

There is no winner or loser at the end of the game. Results are not compared. Players occupy parallel zones. Each player throws a tennis ball into the air, and before catching it again he/she throws a second ball into the air, the aim being to keep both balls in the air using just the one hand. This sequence is performed in different ways over a period of four minutes.

There is cooperative motor interaction between players on the same team.

Each team of 6-8 players competes against another team.

Played in two parallel zones. Two players from each team hold the rope while the others jump over it. The team who jumps for the longest time without making a mistake gains a point. The winner is the team with most points after three rounds.

Teams of 6-8 players are formed. Each team tries to complete the task, but without their results being compared.

Each participant takes the hand of someone else in the group, in no particular order, until a knot of arms is formed. The team is then asked to undo the knot, without any of the participants letting go of another's hand, until a circle is formed. This is performed twice.

Note: The table shows examples of competitive and non-competitive psychomotor and cooperative games. Six sessions were conducted for each domain, using four games per session.

\section{Measuring the intensity of emotions}

We measured the intensity of emotions that participants experienced in each game using the GES (Games and Emotion Scale), validated by Lavega, March, and Filella (2013). For the present sample, the value of Cronbach's alpha indicated that internal consistency was good for the whole scale $(n=218 ; a=.92)$. All students had their own copy of the GES. At the end of each game they were asked to evaluate the intensity they felt for each of the 12 basic positive, negative and ambiguous emotions on a scale from 0 to 10 ), following the model established by Bisquerra et al., (2005), where 0 meant they had not felt that particular emotion, and 10 meant they felt that particular emotion to the full.

\section{Data Analysis}

We examined the normality of the data (i.e., the intensity of the emotions experienced) using the KolmogorovSmirnov test, which indicated a highly skewed distribution, suggesting that we should use non-parametric tests. We therefore decided to use classification trees. Originally developed by Morgan and Sonquist (1963), classification trees are a distribution-free procedure for conducting exploratory analyses. Specifically, the classification or decision tree is an algorithm that can automatically construct contingency tables. This algorithm classifies data on the basis of explanatory variables whose relationship to the response is revealed through different levels of significance or importance. In the present study we used the tree growth method known as CHAID (Chi-squared Automatic Interaction Detector, implemented in SPSS ${ }^{\text {TM }}$ Answer Tree ${ }^{\odot}$ 13.0), as this method is capable of building non-binary trees. Non-binary trees may include more than two data branches or divisions at each node, depending on the categories that have to be explained. We used a cross-validation system with a stopping rule of three maximum levels, with 50 being the minimum number of youth participants at the terminal nodes.

We generated a CHAID classification tree using different predictor variables: (a) the type of game (individual or cooperation), (b) competition (competitive/non-competitive); (c) the type of emotion experienced (positive, negative, or ambiguous), (d) gender (male/female), (e) group gender composition (single-sex, unbalanced mixed-sex, or balanced mixed-sex group), and (f) sporting background (with or without sporting experience). Subsequently, we also generated a classification tree in which the variable type of emotion (i.e., positive, negative, or ambiguous) was replaced by the twelve basic emotions considered, the aim being to identify patterns of results for each one of them. 
Upon completion of this process we held a further 1.5hour session with participants in order to inform them about the significance of the explanatory variables. This opportunity to reflect together on the results also favored greater emotional awareness among the students.

\section{Results}

\section{Predictor Variables of Emotional Experience and Intensity}

The analysis considered 84,288 data items regarding the intensity of the emotions experienced by participants. We generated a classification tree containing 23 nodes that were ordered hierarchically into homogeneous categories corresponding to relationships between the five independent variables and the dependent variable (emotional intensity) for each type of emotion (see Figures 1, 2, and 3).

The hierarchical clustering technique identified significant differences $(p<0.001)$ between the three types of emotions. The highest intensity ratings were for positive emotions $(M=4.63, S D=2.66)$, followed by those for ambiguous emotions $(M=2.19, S D=2.64)$ and, finally, the values for negative emotions $(M=0.74, S D=1.72)$. For the varia- bles studied we identified three patterns of results for each of the three types of emotions (see Figures 1, 2, and 3). These values confirm the initial hypothesis and allow us to present distinct results for each of the three types of emotions.

\section{Predictor Variables of Positive and Ambiguous Emotions}

There were significant differences in results between individual (psychomotor) games and cooperative games ( $p$ $<.001$ ). The main predictor variable for cooperative games was group gender composition: single-sex groups experienced the most intense positive emotions $(M=5.81, S D=$ $2.56)$, followed by balanced mixed-sex groups $(M=5.54, S D$ $=5.54)$, and unbalanced mixed-sex groups $(M=4.78, S D=$ 2.44). For individual games, the best predictor was the variable competition: in these games the presence of a competitive element was associated with higher intensity ratings $(M=$ $4.74, S D=2.71)$ than when no competition was involved $(M$ $=3.48, S D=2.45)$. Gender and group gender composition were not significant variables for individual games (see Figure 1).

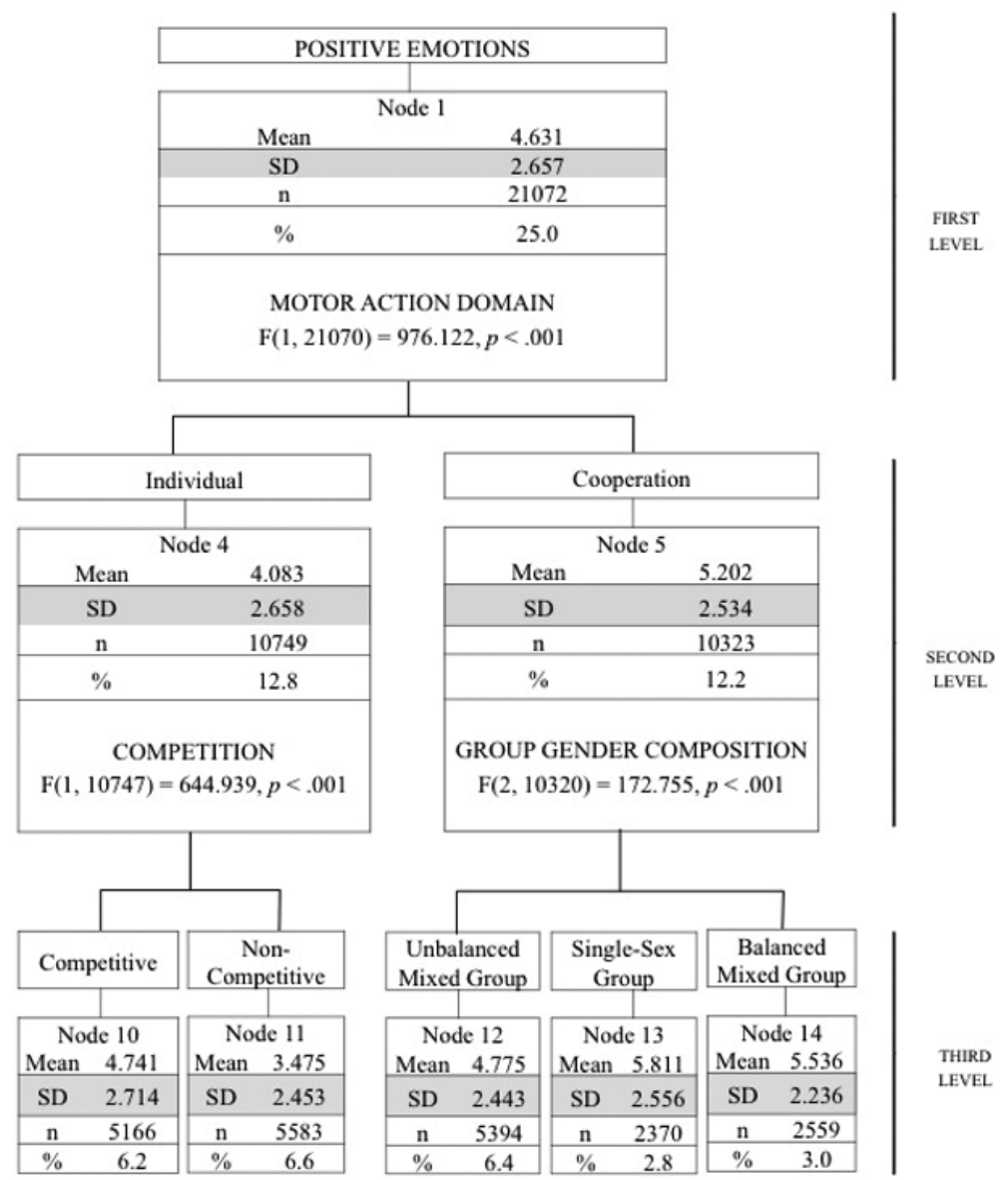

Figure 1. Predictor variables of positive emotions. 
The pattern of results for ambiguous emotions was similar to that observed for positive emotions. The first predictor variable was competition, with higher ratings being associated with competitive $(M=2.48, S D=2.77)$ as opposed to non-competitive games $(M=1.90, S D=3.46, p<.001)$. In competitive games the best predictor variable was group gender composition, with the trend being the same as that observed for cooperative games $(M=2.84, S D=2.89$ in single-sex groups; $M=2.50, S D=2.86$ in balanced mixedsex groups; and $M=2.25$, $S D=2.64$ in unbalanced mixedsex groups). The predictor variable in non-competitive games was the type of game: the intensity ratings for cooperative games $(M=2.11, S D=2.60)$ were higher than those for individual games $(M=1.71, S D=2.31)$. Gender and group gender composition were not significant variables for non-competitive games (see Figure 2).

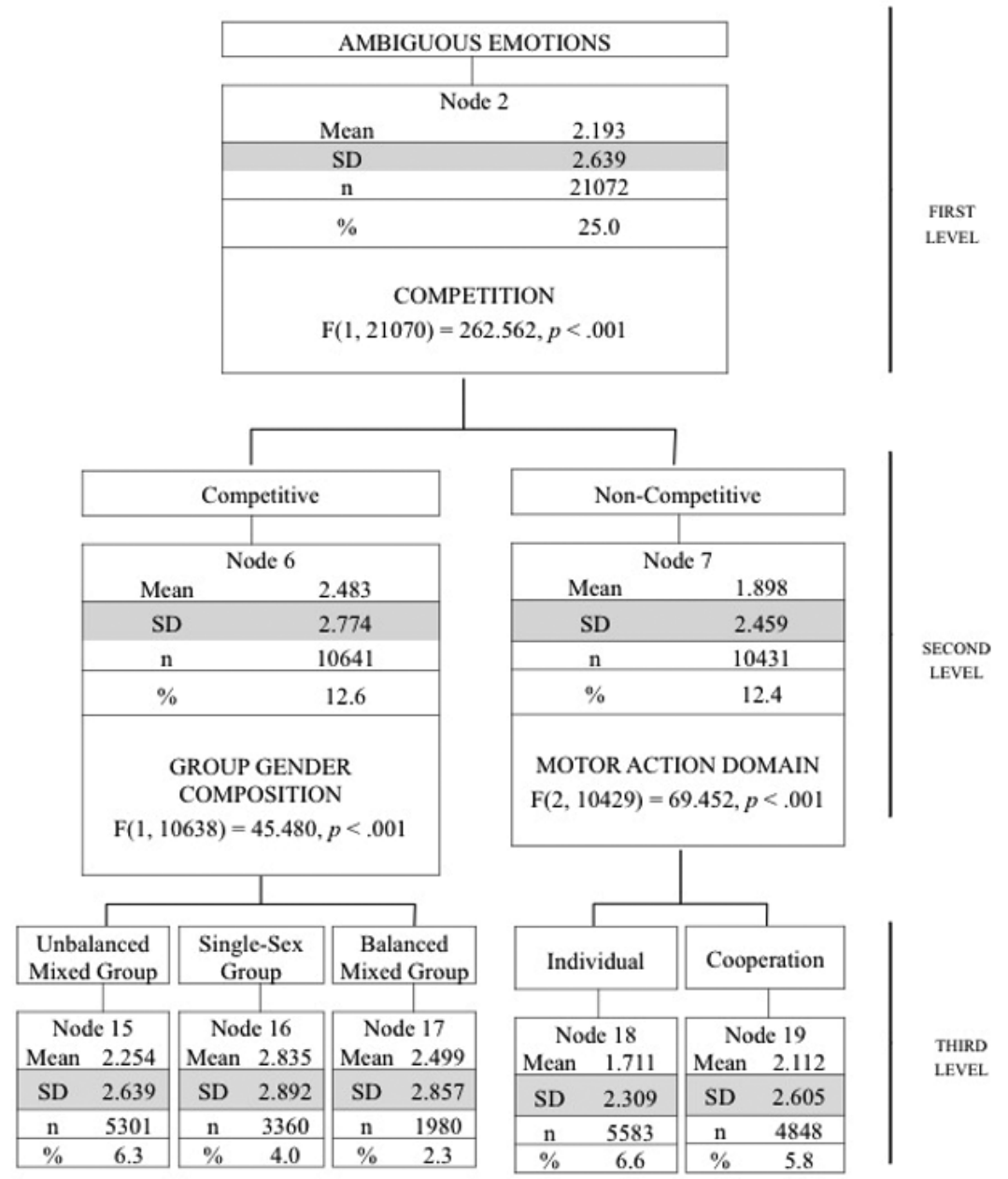

Figure 2. Predictor variables of ambiguous emotions.

\section{Predictor Variables of Negative Emotions}

The main explanatory variable for negative emotions was gender, with males reporting higher intensity ratings than females $(M=0.82, S D=1.81$ vs. $M=0.47, S D=1.38$, respectively; $p<.001)$. The second predictor was previous ex- perience of sport: for both genders those students with a sporting background reported higher intensities of negative emotions $(M=0.84, S D=1.82$ for males and $M=0.50, S D$ $=1.43$ for females) than did those without such a background $(M=0.58, S D=1.60$ for males and $M=0.27, S D=$ 1.03 for females; $p<.001$ ) (see Figure 3 ). 


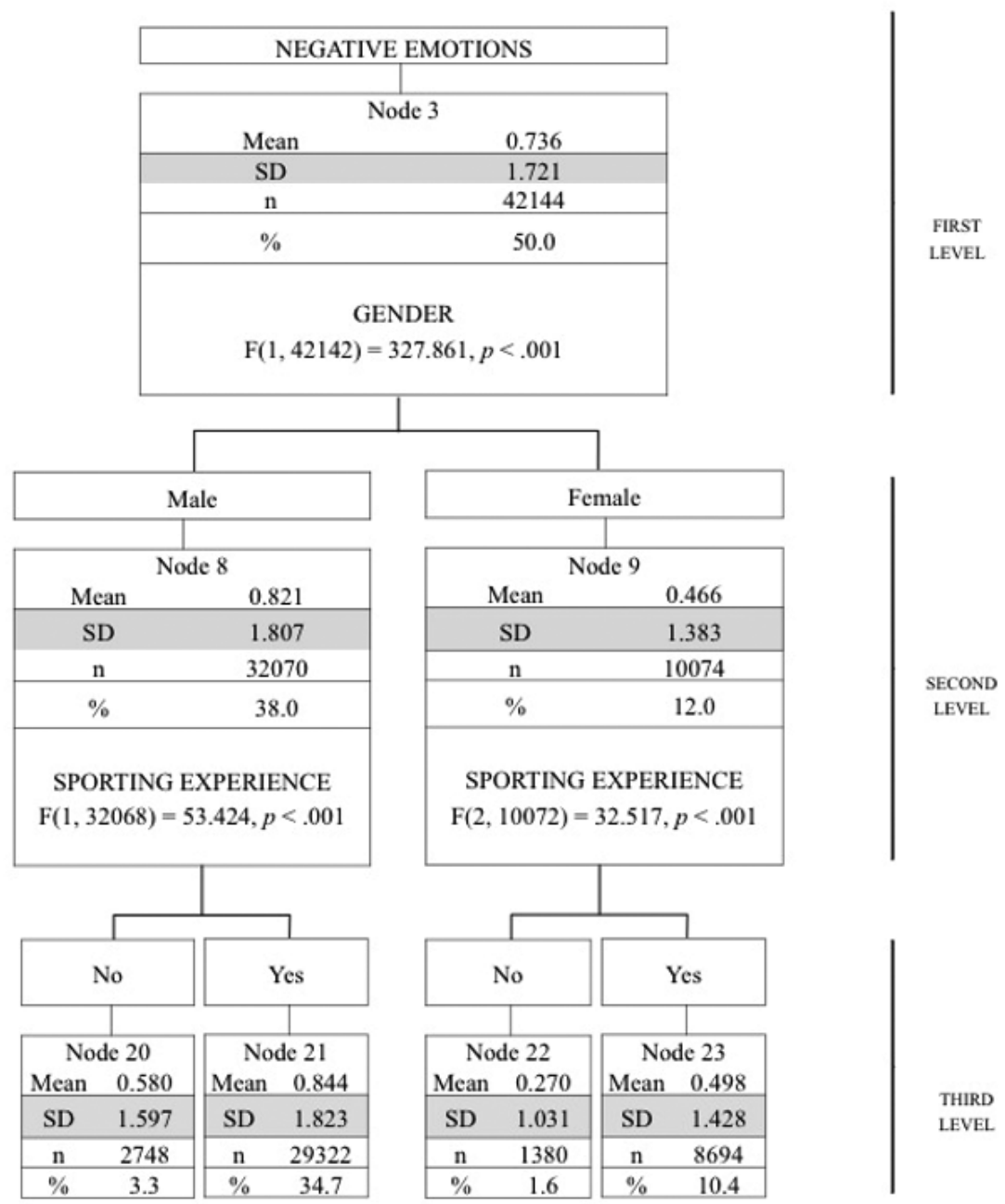

Figure 3. Predictor variables of negative emotions.

Application of the classification tree technique to each of the 12 emotions separately generated 72 nodes and confirmed distinct patterns of results for the emotions belonging to each of the three groups (positive, negative and ambiguous). Significant differences $(\phi<.001)$ were observed between the intensity ratings associated with joy $(M=4.75, S D$ = 2.59), happiness $(M=4.88, S D=2.53)$, humor $(M=4.26$, $S D=2.80)$, surprise $(M=3.14, S D=2.79)$, hope $(M=2.39$, $S D=2.69)$, compassion $(M=1.05, S D=1.90)$, sadness and anxiety (both $M=0.86, S D=1.79)$, fear $(M=0.78, S D=$ 1.83 ), anger and rejection (both $M=0.68, S D=1.71$ ), and shame $(M=0.55, S D=1.44)$.

Each of these 12 emotions reproduced the pattern of results observed in the global analysis of the three types of emotions. In other words, the variables that predicted the intensity of these 12 emotions were the same as those associated with the category of emotion (positive, negative or ambiguous) to which they belonged. For example, the type of game was the main predictor variable for the positive emotion joy, with cooperative games being associated with more intense joy $(M=5.31, S D=2.49)$ than were individual games $(M=4.22, S D=2.59)$. For cooperative games the predictor variable was the group gender composition: the highest intensity ratings for joy were for single-sex groups $(M=6.02, S D=2.41)$, followed by balanced mixed-sex groups $(M=5.83, S D=2.49)$, and unbalanced mixed-sex groups $(M=4.85, S D=2.36)$. For negative emotions such as sadness and anxiety, the best predictor was gender, with males reporting higher intensities of these emotions than did females $(M=0.98, S D=1.89$ vs. $M=0.50, S D=1.38$, respectively; $p<0.001)$. Among male participants, competitive games produced higher intensity ratings than did noncompetitive games $(M=1.14, S D=2.06$ vs. $M=0.81, S D=$ 1.89 , respectively; $p<0.01)$. By contrast, among female participants the difference was related to sporting experience: women with a sporting background reported higher intensities than did those without such a background $(M=0.54$, $S D=1.43$ vs. $M=0.26, S D=1.00$, respectively; $p<0.01)$. 


\section{Discussion}

This study examined the effect of gender (male/female) and group gender composition (single-sex, unbalanced mixedsex, and balanced mixed-sex groups) on male and female undergraduates' experiences of positive, negative and ambiguous emotions when taking part in both competitive and non-competitive individual and cooperative games.

As expected, the first finding of note was that each of the three categories of emotions produced a different pattern of results. Furthermore, the results for the 12 specific emotions were consistent with the pattern of results for the category to which they belonged. These findings confirm the first hypothesis, and therefore the consistency of the theoretical construct of emotions that we used in the study (Bisquerra et al., 2005; Lazarus, 2000) and that other, previous studies also used (Lavega, Aráujo et al., 2013; Lavega et al., 2014).

\section{Predictors of positive and ambiguous emotions}

As predicted in hypothesis 2, gender, group gender composition and type of game were the best predictors for generating high-intensity positive and ambiguous emotions among participants.

The results showed that the experience of positive emotions differed significantly between individual (psychomotor) and cooperative games. This is consistent with the fact that these two families of games imply very different kinds of motor relationships for participants (Parlebas, 2001).

In cooperative games involving a competitive element, group gender composition was the best predictor of the experience of positive and ambiguous emotions. Games of this kind require participants to help one another and they are obliged to reach agreement and interact in ways that increase the likelihood of achieving the common goal (Lavega et al., 2014; Parlebas, 2001). Given such a social context for motor behavior (Etxebeste, 2012), it is understandable that the gender composition of the group might affect participants' experiences of the emotions as they engage in these kinds of activities.

When we placed them in single-sex groups, both male and female students reported experiencing more intense positive and ambiguous emotions. Indeed, joy, happiness, and humor were all more intense when students cooperated with peers of the same sex. This could be related to cultural stereotypes of masculinity and femininity, as well as to the fact that cooperative games of this kind have traditionally been played more by girls than by boys. By being accustomed to playing games of this sort, girls are able to feel more intense positive emotions, especially when playing with or competing against other girls. A further point that has been made previously by other researchers is that in single-sex groups both genders perceive greater opportunities and compete in more homogeneous conditions, improving the chances of achieving the proposed objective (Keinman, 1999; Williams, 2010).

In mixed groups, the emotions experienced were more intense when there were equal numbers of male and female participants, rather than a predominance of males. This suggests that in balanced mixed groups both teams see themselves as having equal resources, which favors a more intense emotional experience. This can be illustrated by considering two cooperative games that are traditionally associated with one sex or the other. In the game of leapfrog, two teams compete to be the first to reach the other end of the sports hall. Participants must vault quickly over their teammates, who will be lined up and bending forward. This kind of traditional game is popular among boys (Etxebeste, 2012; Lavega, 2006), so the team with fewer females will tend to win. By contrast, in the rope-jump game each team has its own area in which to jump, and the aim is to jump as many times as possible without making a mistake. As this game is traditionally popular among girls (Etxebeste, 2012; Lavega, 2006), a team comprised solely of males is likely to perform worse than a mixed-sex team. Imbalances of this kind may have a negative impact not only on the positive emotions that are experienced, but also on ambiguous emotions such as surprise (which might otherwise have been felt when winning) or hope (when losing despite having expected to win). Overall, these findings illustrate how, in cooperative games, motor intelligence is linked to both social intelligence and emotional intelligence.

Individual games do not involve any motor interaction among participants; rather, success or failure depends solely on the individual, as nobody else can help or hinder him or her. Consequently, in these games, social variables such as gender or group gender composition do not act as predictors of the experience of positive or ambiguous emotions. It is worth noting, however, that both positive and ambiguous emotions are experienced more intensely when a competitive element is introduced. As authors such as Navarro and Trigueros (2009), Etxebeste (2012), and Lavega et al. (2014) have pointed out, the competitive element is a factor that encourages interest among participants who are asked to perform repetitive skill drills (e.g. repeatedly throwing a bowling bowl at a set of skittles).

\section{Gender of Participants as a Main Predictor of Nega- tive Emotions}

As predicted by hypothesis 3, gender and gender group composition were the main predictors of negative emotions.

In contrast to what we observed for positive and ambiguous emotions, the variables that explained the experience of negative emotions were all related to factors external to the game itself (e.g. gender or group gender composition). This means that an emotional appraisal of this kind depends primarily on the characteristics of those taking part. In this regard, we need to be aware that the gender of participants is the best predictor of emotions such as anger, rejection and 
anxiety, with males reporting more intense experiences in this regard. These findings confirm those of previous studies, indicating that males and females experience negative emotions differently (Brody \& Hall, 2008; Hertenstein \& Keltner, 2011; Hess et al., 2000; Sáez de Ocáriz et al., 2013).

The finding that the second factor to consider in relation to these emotions was sporting experience is not surprising, given that the majority of these students $(81.2 \%)$ regularly took part in some kind of sport. More specifically, those students - male and female - with a sporting background experienced more intense negative emotions than did their peers with no such background. This can be explained by the fact that the former are used to becoming emotionally involved in competitive encounters and, therefore, in situations that imply a hierarchy in the form of ranked power relations associated with winning or losing (Berg \& Lahelma, 2010). Consequently, students with a sporting background are more affected by winning or losing than are students without previous experience of competitive sport. A further point is that the two groups of students will probably have internalized different stereotypes into their sense of self during the socialization process (Chalabaev et al., 2013; Johnson et al., 2011).

The findings derived from the classification trees highlight the importance of PE teachers being aware that certain variables may influence students' emotional experiences. Among these variables, particular attention should be paid to the gender of participants and the group gender composition, since they are predictor variables for the three types of emotions.

This study is limited by the fact that the sample comprised solely undergraduates, most of whom had previous experience of competitive sport. This aspect needs to be addressed in future studies. The study was conducted within the context of an experience designed to raise prospective PE teachers' awareness of the importance of emotional intelligence. In a second phase, we intend to extend the analysis to primary and secondary school students. Given the topic of this study (emotions), another limitation is that emotional issues such as self-esteem and self-efficacy have not been addressed, so this will also need to be done in future studies.

\section{Conclusions}

This research has produced a set of scientific criteria that could be applied to PE programs that seek to promote gender equity and subjective well-being (Ciarrochi \& Scott, 2006; Diener, 2009; Johnson et al., 2011; Lavega et al., 2014;

\section{References}

Beltrán-Carrillo, V.J., Devís-Devís, J., Peiró-Vlert, C., \& Brown, D.H.K. (2012). When physical activity participation promotes inactivity: Negative experiences of Spanish adolescents in physical education and sport. Youth \& Society, 44(1), 3-27. doi: 10.1177/0044118X10388262

Berg, P., \& Lahelma, E. (2010). Gendering processes in the field of physical education. Gender and Education, 22(1), 31-46. doi: $10.1080 / 09540250902748184$
Vera et al., 2009). Indeed, the results highlight the need to consider individual gender and group gender composition as predictors of emotional experience during sport games. In this regard, any $\mathrm{PE}$ teacher who opts to use cooperative games should be aware that the gender composition of a group has a direct impact on the intensity of the emotions experienced by participants (Berg \& Lahelma, 2010; Keinman, 1999). One dilemma that arises as a result of this is whether to organize single-sex groups so that students feel more positive emotions or to encourage interpersonal relationships between male and female participants at the expense of less intense emotional experiences. A further point that PE teachers need to be aware of is that, in both individual (psychomotor) and cooperative games, males are more likely than females to experience negative emotions.

It is important to highlight that this study contributes to understanding gender relations in Spain from the perspective of PE. In Spain today, gender relations are being transformed. In addition to the hegemonic gender cultures that already exist, in which male and female gender roles are highly stereotyped, new cultures are emerging in which gender identities are more blurred and less subject to traditional rules in society.

Sport reflects these transformations, with these two hegemonic gender cultures (male and female) coexisting. Sundry other subcultures have emerged, with women taking part in football, rugby, boxing, triathlons, marathons and bodybuilding, and men taking part in gentle gym workouts, yoga, meditation and dance (Puig, 2002; Puig \& Soler, 2003)

The results of our research, however, have shown no break away from traditional gender stereotypes; the emotional experiences and intensities of male and female participants were in line with those stereotypes. PE teachers are therefore faced with a major challenge, since in addition to introducing activities to improve students' emotional education, they must also seek to use activities that will create gender identities that are more in line with each student's wishes, rather than with the stereotypical understanding that some sectors of society have of what a man or woman should be.

Acknowledgements.- This work was supported by Spain's Ministry of Science and Innovation under Grant numbers DEP201021626-C03-01, DEP2010-21626-C03-02, DEP2010-21626-C03-03; and Catalonian National Institute of Physical Education (INEFC) under Grant number 2014PINEFC/00002. The authors would like to thank Óscar Farrús (INEFC-Lleida) for his help with the use of new technology to gather and process the data.

Bisquerra, R. (2003). Bisquerra, R. (2003). Educación emocional y competencias básicas para la vida [Emotional education and basic life competencies]. Revista de Investigación Educativa, 21, 7-43.

Bisquerra, R., Soldevila A., Ribes R., Filella, G., \& Agulló, M. J. (2005). Una propuesta de currículum emocional en educación infantil (3-6 años). C \& E: Cultura y educación, 17(1), 5-18. 
Bolaños, L. M., \& Jiménez, R. (2007). La formación del profesorado en género. [Teacher training in gender issues]. Revista de Investigación Educativa, 25, 77-95.

Brody, L. R., \& Hall, J. (2008). Gender and emotion in context. In M. Lewis, J. M. Haviland-Jones, \& L. F. Barrett, (Eds.), Handbook of emotions (pp. 395-408). New York: The Guilford Press.

Castillo, R., \& Montes, B. (2014). Análisis de los estereotipos de género actuales [Analysis of current gender stereotypes]. Anales de Psicología, 30(3), 1044-1060. doi: http://dx.doi.org/10.6018/analesps.30.3.138981

Chalabaev, A., Sarrazin, P., Fontayne, P., Boiché, J., \& Clément-Guillotin, C. (2013). The influence of sex stereotypes and gender roles on participation and performance in sport and exercise: Review and future directions. Psychology of Sport and Exercise, 14, 136-144.

Ciarrochi, J., \& Scott, G. (2006). The link between emotional competence and well-being: A longitudinal study. British Journal of Guidance \& Counselling, 34(2), 231-243. doi: 10.1080/03069880600583287

Del Castillo, O., Romero, S., González, T., \& Campos, M. C. (2012). Gender equity in physical education: The use of information. Sex Roles, 67, 108-121. doi: 10.1007/s11199-011-0103-5

Denham, S. A., Bassett, H. H., \& Wyatt, T. (2007). The socialization of emotional competence. In J. Grusec \& P. Hastings (Eds.), The handbook of socialization (pp. 614-637). New York: Guilford Press.

Diener, E. (2009). Subjective well-being. In E. Diener (Ed.), The science of well-being (pp. 11-58). New York: Spring.

Etxebeste, J. (2012). À cloche-pied. Les jeux sportifs traditionnels et la socialisation des enfants basques [Hopping on one leg. Traditional sports games and the socialization of Basque children]. Sarrebruck: Editions universitaires européennes.

Gartzia, L., Aritzeta, A., Balluerka, N., \& Barberá, E. (2012). Inteligencia emocional y género : más alla de las diferencias sexuales [Emotional intelligence and gender: beyond gender differences]. Anales de Psicología, 28(2), 567-575. doi : http://dx.doi.org/10.6018/analesps.28.2.124111

Gutiérrez, M., Ruiz, L. M., \& López, E. (2010). Perceptions of motivational climate and teachers' strategies to sustain discipline as predictors of intrinsic motivation in physical education. The Spanish Journal of Psychology, 13, 597-608.

Hertenstein, M. J., \& Keltner, D. (2011). Gender and the communication of emotion via touch. Sex Roles, 64, 70-80. doi: 10.1007/s11199-010-9842

Hess, U., Senécal, S., Kirouac, G., Herrera, P., Philippot, P., \& Kleck, R. E. (2000). Emotional expressivity in men and women: Stereotypes and self-perceptions. Cognition \& Emotion, 14, 609-642.

Hochschild, A. R. (1983). The managed heart. Commercialization of buman feelings. Berkeley: University of California Press.

Johnson, T. G., Prusak, P. A., Pennington, T., \& Wilkinson, C. (2011). The effects of the type of skill test, choice, and gender on the situational motivation of physical education students. Journal of Teaching in Physical Education, 30, 281-295.

Keinman, I. (1999). Should PE classes return to teaching males and females separately? Journal of Physical Education, Recreation and Dance, 70, 11-12.

Kennedy-Root, A., \& Denham, S. A. (2010). The role of gender in the socialization of emotion: Key concepts and critical issues. New Directions for Child and Adolescent Development, 1,1-9. doi: 10.1002/cd.265
Lavega, P. (Ed.) (2006). Traditional games and society in Europe: European culture in the light of traditional games and sports. Barcelona: European Association of Traditional Games and Sports, INEFC-University of Lleida.

Lavega, P., Alonso, J. I., Etxebeste, J., Lagardera, F., \& March, J. (2014). Relationship between traditional games and the intensity of emotions experienced by participants. Research Quarterly for Exercise and Sport, 85, 457-467. doi: 10.1080/02701367.2014.961048

Lavega, P., Aráujo, P., \& Jaqueira, A.R. (2013). Teaching motor and emotional competencies in university students. Cultura, Ciencia y Deporte, 9(8), 5-15.

Lavega, P., Filella, G., Lagardera, F., Mateu, M., \& Ochoa, J. (2013). Juegos motores y emociones. Cultura y Educación, 25(3), 347-360.

Lavega, P., March, J., \& Filella, G. (2013). Juegos deportivos y emociones. Propiedades psicométricas de la escala GES para ser aplicada en la Educación Física y el Deporte. [Psychometric properties of the Games and Emotions Scale (GES): An instrument for application in the context of physical education and sport]. Revista de Investigación Educativa, 31(1), 151-166.

Lazarus, R. S. (1991). Emotion and adaptation. New York: Oxford University Press.

Lazarus, R. S. (2000). How emotions influence performance in competitive sports. The Sport Psychologist, 14, 229-252.

Morgan, J. N., \& Sonquist, J. A. (1963). Problems in the analysis of survey data. Journal of the American Statistical Association, 58, 415-434.

Navarro, V., \& Trigueros, C. (Eds.) (2009). Investigación y juego motor en España [Research and motor games in Spain]. (pp. 77-116). Lleida: University of Lleida.

Parlebas, P. (2001). Juegos, deporte y sociedad. Léxico comentado en praxiología motriz. [Games, sport and society: An annotated vocabulary of motor praxeology]. Barcelona: Paidotribo.

Puig, N. (2002). Weibliche Differenz im Sport. Die Situation der Frauen im Sport zu Beginn des neuen Jahrhunderts [Female difference in sport: The position of women in sport at the turn of the century]. Sportwissenschaft, 32(1), 48-67.

Puig, N., \& Soler, S. (2003). Women and Sport in Spain. In I. HartmannTews, \& G. Pfister (eds.). Sport and women. Social issues in international perspective. (pp. 83-101). London and New York: Routledge, International Society for Comparative Physical Education and Sport.

Sáez de Ocáriz, U., Lavega, P., \& March, J. (2013). El profesorado ante los conflictos en la educación física. El caso de los juegos de oposición en educación primaria. [Teachers faced with conflicts in physical education. The case of opposition games in primary school]. Revista Electrónica Interuniversitaria de Formación del Profesorado,16(1), 163-176. doi: http://dx.doi.org/10.6018/reifop.16.1.180101

Schutz, P. A., \& Pekrun, R. (Eds.) (2007). Emotions in education. San Diego: Academic Press.

Vera, J. A., Moreno, R., \& Moreno Murcia, J. A. (2009). Relationships between the transfer of responsibility in assessment and the perception of equality in physical education classes. Cultura, Ciencia y Deporte, 4(3), 2531.

Williams, S. M. (2010). Physical activity levels in coed and same-sex physical education using the tactical games model. Utah: University of Utah.

(Article received: 09-06-2016; revised: 23-11-2016; accepted: 06-12-2016) 